\title{
The price of personal mobility: burden of injury and mortality from personal mobility devices in Singapore - a nationwide cohort study
}

Aidan Lyanzhiang Tan ${ }^{1}$, Trauma Coordinators and Trauma Service Representatives ${ }^{2}$, Nivedita Nadkarni ${ }^{3}$ and Ting Hway Wong ${ }^{4,5^{*}}$ (D)

\begin{abstract}
Background: Personal mobility devices (PMDs) like skate-scooters, electric bicycles (e-bikes) or motorised scooters (e-scooters) have become widely available globally. There are several studies describing the rising incidence of injury from such devices. The aim of our study was to examine PMD user factors between motorised (MotPMDs) vs non-motorised PMDs (NonPMDs) as risk factors for severe injury and the need for hospital admission.

Methods: We analysed de-identified National Trauma Registry data (2015 to 2017) from all public sector hospitals in Singapore for patients aged 12 and above presenting to emergency departments with PMD-related injuries. Multivariable logistic regression was used to identify risk factors for the primary outcome of interest (higher injury severity, defined as Injury Severity Score / ISS > =9), and the secondary outcome of interest (need for hospital admission). Additional subgroup analysis was conducted comparing only scooters (manual vs electric), the most common sub-type of PMD in our study.

Results: Of the 614 patients in our study, majority were male (74\%), median age 33 years, with 136 (22\%) sustaining injuries with ISS > =9; 185 (30\%) admitted [median stay length 3 days (IQR: 1-6)] and 93 (15\%) required surgery. MotPMDs were more common $(480,78 \%)$, with e-scooters being the most common motorised device (393, 64\%). There were 6 deaths, all in MotPMD users.

On both univariate and multivariable regression, MotPMD users [OR 3.82, 95\% Cl 1.51-12.9, $p=0.01$ ] and older users ( $>=60$ years) [OR 9.47, 95\% Cl 2.45-62.9, $p=0.004]$ were more likely to sustain injuries with ISS $>=9$, and more likely to need admission (MotPMD users [OR 1.8, 95\% Cl 1.04-3.29, $p=0.045$ ], age $>=60$ years [OR 4.72, 95\% Cl 1.86-13.0, $p=0.002]$ ).

Conclusion: MotPMDs tripled the risk of severe injury and doubled the risk of requiring hospitalisation, compared to NonPMDs, likely due to higher travelling speeds. Increased age was also associated with severe injury and requiring hospitalisation.
\end{abstract}

Keywords: Trauma, Personal mobility devices, E-scooters, Injury severity, Injury prevention, Singapore, Asia

\footnotetext{
* Correspondence: wong.ting.hway@singhealth.com.sg;

wong.th@doctors.net.uk

${ }^{4}$ Singapore General Hospital/Duke-National University of Singapore Graduate

Medical School, Outram Road, Singapore 169608, Singapore

${ }^{5}$ Department of General Surgery, Singapore General Hospital, Outram Road,

Singapore 169608, Republic of Singapore

Full list of author information is available at the end of the article
}

(c) The Author(s). 2019 Open Access This article is distributed under the terms of the Creative Commons Attribution 4.0 International License (http://creativecommons.org/licenses/by/4.0/), which permits unrestricted use, distribution, and reproduction in any medium, provided you give appropriate credit to the original author(s) and the source, provide a link to the Creative Commons license, and indicate if changes were made. The Creative Commons Public Domain Dedication waiver (http://creativecommons.org/publicdomain/zero/1.0/) applies to the data made available in this article, unless otherwise stated. 


\section{Background}

Personal mobility devices (PMDs), such as skatescooters, and motorized personal mobility devices such as electric bicycles (e-bikes) or motorised scooters (escooters) have rapidly increased in popularity globally. There has been a corresponding rise in PMD-related injury [1-5], with unusual injury patterns being described $[1,6]$, particularly with hoverboards [7-11].

Motorised PMD (MotPMD) users, in particular, appear to be at greater risk of injury $[5,12,13]$. Reasons proposed include greater risk-taking behaviour for MotPMD users compared to non-motorised PMD users (NonPMDs) [14-17], and environmental separation issues (pedestrian vs bicycle lanes vs roads) [18]. MotPMDs also travel at much higher speeds than NonPMD [4, 17, 19]. While there appears to be a higher risk of injury for MotPMD users [5], there are very few studies evaluating the relationship between PMD type (MotPMD vs NonPMD) and the severity of injury. Existing studies have so far only evaluated e-bikes in relation to conventional bicycles, but other MotPMD types such as e-scooters are becoming more popular $[12,13]$.

In Singapore, trauma is the leading cause for hospitalisation, and one of the major causes of mortality [20]. The Singapore National Trauma Registry (NTR) was established in 2011, covering all public hospitals in Singapore. Using NTR information, our primary goal was to identify and evaluate risk factors for higher injury severity (Injury Severity Score, ISS > =9) [21, 22], and for inpatient hospital admission in PMD users.

\section{Methods}

\section{Data source and data collection}

This retrospective national cohort study was conducted using NTR data from all adult public-sector hospitals in Singapore. The NTR covers all public hospitals in Singapore, with coding and data collection conducted by trained trauma data coordinators with annual data quality checks (covering accuracy, reliability, completeness and validation) performed annually. Quarterly review of data capture is performed by the National Registry of Diseases Office. The registry inclusion criteria, data collection, data cleaning and data quality audit processes have been described in previous studies [23-25].

\section{Study design}

Retrospective data from January 2015 to December 2017 was extracted and de-identified by the public hospital trauma units, with 1 site contributing data only for 2015-2016, and another site providing only 2016 data. The associations between patient demographics, PMD types (MotPMD vs NonPMD), and outcomes of interest (injury severity and need for hospitalization) were examined.

\section{Study population}

We included patients aged 12 years and older who presented at the public-sector hospital emergency departments with PMD-related injuries. We excluded injuries related to: motorised wheelchairs, roller blades, and bicycles. Although pedestrians injured by PMDs would contribute to the burden of injury by PMDs, the data collection definitions for pedestrians injured by PMDs had not been standardized across the sites at the time of this study, as the NTR categories had focussed on PMD riders, hence we excluded pedestrians injured by PMDs.

\section{Outcome measures}

The primary outcome measure was higher injury severity, defined as injuries with an ISS of 9 or higher [21, 22].

The second outcome measure was the need for hospital admission, as a proxy for healthcare utilization and costs.

\section{Covariates}

Patient demographics, PMD details, need for admission, and whether surgery was performed, were extracted from the NTR. Age was analyzed in these age-bands: $12-19$ years, 20 to 39 years, 40 to 59 years, and 60 years or older.

PMDs were grouped into the following categories: MotPMDs (hoverboards/unicycles/e-wheels, motorised bicycles/e-bikes/powered assisted bicycles, motorised scooters/escooters, motorised skateboards), and NonPMDs (nonmotorised scooters - including kick scooters or selfbalancing scooters, and skateboards). PMD rider position was collected where available, where the patient was either the main rider, or a passenger/pillion rider on the PMD. For sites where information on injury prevention protective gear was collected, helmet use was examined.

\section{Statistical testing}

Overall patient characteristics were summarized by mean (standard deviation), median (inter-quartile range), or frequency (\%) as appropriate.

Linear predictors of interest were re-categorised (for example, age into age-bands) for analysis. Logistic regression was used to examine the association between the variables and outcomes of interest.

Variables identified as having statistically significant associations $(p<0.05)$ in the univariate regression were included in the multivariable logistic regression model. Variables not statistically significant but clinically meaningful (gender) were also included.

As the morphology of injury due to different PMD types may differ, additional subgroup analysis was conducted of scooters only, comparing electric and nonelectric scooters.

$R$ version 3.4.3 was used. 


\section{Ethical issues}

Ethical approval by the corresponding author's institution's institutional review board was granted, with waiver of informed consent granted as only secondary retrospective and de-identified data was used.

\section{Results}

\section{Descriptive analysis}

We identified 732 potentially eligible patients from the registry and excluded 12 as being below 12 years old. The following patients were excluded for not meeting the criteria of a PMD rider: 89 (pedal cycles), 12 (roller blades) and 1 (motorised wheelchair), and 4 pedestrians injured by PMDs. Of the remaining 614 patients, majority were main riders $(n=600,97 \%)$, the remainder were pillion riders. Users with undocumented PMD type ( $n=$ 42) were included in the overall descriptive analysis (of 614 patients) but excluded from the comparison of MotPMD vs NonPMD (572 patients).

For the 614 PMD riders, the median age was 33 years old (IQR: $24-46$ years). Males accounted for $76 \%$ of the sample $(n=465)$. The predominant type of MotPMD used was motorised scooters/e-scooters $(n=393,64 \%)$, followed by motorised bicycles/e-bikes/powered assisted bicycles $(n=$ $63,10 \%)$. The most common NonPMD were scooters $(n=$ $47,8 \%)$ and skateboards $(n=45,7 \%)$. For 131 patients, use of injury prevention protective gear was documented, and only a minority wore helmets $(n=18,14 \%)$.

Median ISS was 2 (IQR: 1-5), with almost a quarter sustaining significant injury (ISS $>=9)(n=136,22 \%)$, and more than a quarter of patients requiring admission $(n=185,30 \%)$. The average length of stay was 3 days (IQR 2-6). Only 1 in 6 patients required surgical intervention $(n=93,15 \%)$. Of the 614 patients, 6 died $(0.97 \%) ; 3$ aged between 40 and 59 years, and 3 aged more than 60 years of age. All 6 deaths were in MotPMD users (Table 1).

Riders of MotPMDs tended to be older (median age 34 vs 25 years for non-motorized, $p<0.01$ ). Gender distribution was similar between the two groups. More MotPMD users had significant injuries (19\% vs $4 \%, p<$ 0.01 ), and more required admission ( $33 \%$ vs $18 \%, p<$ 0.01 ). The proportion requiring surgery was similar between the groups (Table 1).

\section{Univariate Analysis}

MotPMD users were more likely to sustain significant injury (ISS $>=9)$ (OR 5.08, 95\% CI 2.05-16.9, $p=0.002$ ). Older age was also associated with sustaining higher injury severity (age-group 60 years and above, OR 4.03, 95\% CI 1.59-11.28, $p<0.01$ ). MotPMDs (OR 2.16, 95\% CI $1.26-3.90, p=0.007$ ) and the older age group (OR 4.75, $95 \%$ CI 2.02-11.9, $p=0.001$ ) were both associated with increased likelihood of hospital admission (Table 2).

\section{Multivariable analysis}

MotPMD use (OR 3.82, 95\% CI 1.51-12.9, $p=0.01$ ), male gender (OR 1.82, 95\% CI 1.00-3.51, $p=0.06$ ) and the older age groups (40-59 years, OR $4.88,95 \% \mathrm{CI}$ $1.36-31.2, p=0.04$, and $>=60$ years, OR 9.47, 95\% CI $2.45-62.9, p<0.01)$ were significantly associated with sustaining severe injury (ISS $>=9$ ).

Only MotPMD use (OR 1.80, 95\% CI 1.04-3.29, $p=$ 0.045 ) and the older age group ( $>=60$ years) (OR 4.72 , $95 \%$ CI 1.86-13.0, $p=0.002)$ were significantly associated with hospital admission on multivariable analysis (Table 2). Male gender showed a slightly higher risk of admission, but this was not statistically significant (OR1.23, 95\% CI 0.79-1.94, $p=0.36$ ).

\section{Subgroup analysis - E-scooter vs non-motorised scooters} We compared 393 e-scooter users against 47 nonmotorised scooter users. Age $>=60$ years (OR 6.0, 95\% CI $0.99-115, p=0.10$ ), male gender (OR 2.24, 95\% CI 1.07-5.30, $p=0.04$ ) and MotPMD use (OR 3.78, 95\% CI 1.11-23.7, $p=0.07$ ) were associated with sustaining significant injury, although age fell short of significance on multivariable analysis (Table 3).

\section{Discussion}

To our knowledge, our study is the first to examine factors associated with injury severity and hospitalization in personal mobility device riders across a range of PMD types, using data that is nationally representative in an urban city state. Other studies have focused on specific types of PMDs. We found that MotPMD users had higher injury severity scores, with a greater proportion requiring surgical intervention compared to NonPMD users, as has been reported by other authors $[5,18]$. Our study, however, is one of the few that included a NonPMD comparator group, suggesting that MotPMD users are at higher risk of injury compared to NonPMD users.

MotPMD use and older age were identified as factors independently associated with severe injury. A similar pattern was found in the subgroup analysis of escooters, although this only reached statistical significance for severe injury, possibly due to smaller subgroup sample size. This is in keeping with the findings from studies conducted in China and Switzerland [3, 13], focusing on pedal cycles versus electric-bicycle users, which also found higher injury severity for electricbicycle users.

Older age was associated with higher risk of significant injury or admission, likely due to higher fall risk and frailty. Studies of motor vehicle crashes have also shown that the older patients tend to sustain higher injury severity and mortality [25-29]. In common with motor vehicle crash-injured patients, older PMD riders are likely to have reduced physiological reserves and impaired 
Table 1 PMD riders descriptive statistics

\begin{tabular}{|c|c|c|c|c|c|c|c|}
\hline \multirow{2}{*}{$\overline{T \text { Total }}$} & & \multicolumn{2}{|c|}{$\begin{array}{l}\text { Overall } \\
\text { Number (\%) }\end{array}$} & \multicolumn{2}{|c|}{$\begin{array}{l}\text { Non-motorised PMD users } \\
\text { Median (IQR) / Mean (SD) }\end{array}$} & \multicolumn{2}{|c|}{ Motorised PMD users } \\
\hline & & 614 & & 92 & & 480 & \\
\hline \multirow[t]{4}{*}{ Age $(\text { years })^{\dagger}$} & 12 to 19 & 48 & (8\%) & 18 & $(20 \%)$ & 25 & $(5 \%)$ \\
\hline & 20 to 39 & 347 & $(57 \%)$ & 56 & $(61 \%)$ & 267 & $(56 \%)$ \\
\hline & 40 to 59 & 168 & $(27 \%)$ & 16 & $(17 \%)$ & 141 & $(29 \%)$ \\
\hline & $>=60$ & 51 & $(8 \%)$ & 2 & $(2 \%)$ & 47 & $(10 \%)$ \\
\hline Gender & Females & 149 & $(24 \%)$ & 20 & $(22 \%)$ & 111 & $(23 \%)$ \\
\hline \multirow[t]{7}{*}{ Personal Mobility Device (PMD) Type } & Motorised scooter / e-scooter & 393 & $(64 \%)$ & - & & 393 & (82\%) \\
\hline & $\begin{array}{l}\text { Motorised bicycle / ebike / powered } \\
\text { assisted bicycle }\end{array}$ & 63 & $(10 \%)$ & - & & 63 & $(13 \%)$ \\
\hline & Hoverboards / unicycle / e-wheel & 22 & $(4 \%)$ & - & & 22 & $(5 \%)$ \\
\hline & Motorised skateboard & 2 & $(0.30 \%)$ & - & & 2 & $(0.45 \%)$ \\
\hline & Scooter - kickscooter, self balancing & 47 & $(8 \%)$ & 47 & $(51 \%)$ & - & \\
\hline & Skateboard & 45 & $(7 \%)$ & 45 & $(49 \%)$ & - & \\
\hline & Undocumented PMD type & 42 & $(7 \%)$ & - & & - & \\
\hline Protective Gear Use & Helmet used (data available for 131 riders) & 18 & $(14 \%)$ & 0 & $(0 \%)$ & 17 & $(4 \%)$ \\
\hline \multirow[t]{2}{*}{ Riding Position } & Main Rider & 600 & $(98 \%)$ & 92 & $(100 \%)$ & 469 & (98\%) \\
\hline & Pillion / Passenger & 14 & $(2 \%)$ & 0 & $(0 \%)$ & 11 & $(2 \%)$ \\
\hline Injury Details ${ }^{\dagger}$ & $\mid S S>=9$ & 136 & $(22 \%)$ & 4 & $(4 \%)$ & 90 & (19\%) \\
\hline \multirow[t]{3}{*}{ Treatment Details } & Admitted $^{\dagger}$ & 185 & $(30 \%)$ & 17 & $(18 \%)$ & 159 & (33\%) \\
\hline & Average Length of Stay (days) & 3 & $(2-6)$ & 3 & $(2-6)$ & 3 & $(1-6)$ \\
\hline & Required Surgery & 93 & $(15 \%)$ & 10 & $(11 \%)$ & 81 & $(17 \%)$ \\
\hline Deaths & & 6 & $(0.97 \%)$ & 0 & $(0 \%)$ & 6 & $(1.25 \%)$ \\
\hline
\end{tabular}

${ }^{\dagger}$ Statistically significant $(p<0.05)$ difference between Motorised and Non-Motorised PMD users

response to injury [30-32], coupled with comorbid conditions that predispose to injury or further reduce resilience [32, 33], and propensity for fracture even with minor trauma [34]. In addition, older riders are probably choosing to ride MotPMDs to overcome their pre- existing musculoskeletal problems, and these patients may be more frail than younger patients to begin with.

While our study did not specifically examine PMD rider behaviour, we did find that the majority of the MotPMD users did not use protective helmets, in line

Table 2 Factors associated with severe injury or need for admission $(n=572)$

\begin{tabular}{|c|c|c|c|c|c|c|c|}
\hline \multirow{2}{*}{$\begin{array}{l}\text { Outcome } \\
\text { Severe Injury }\end{array}$} & \multirow{2}{*}{$\begin{array}{l}\text { Variables } \\
\text { Motorised PMD (ref non-motorised) }\end{array}$} & \multicolumn{3}{|c|}{$\begin{array}{l}\text { Univariate } \\
\text { Odds Ratio, }(95 \% \text { CI), p value }\end{array}$} & \multicolumn{3}{|c|}{$\begin{array}{l}\text { Multivariable } \\
\text { Odds Ratio, (95\% Cl), p value }\end{array}$} \\
\hline & & 5.08 & $(2.05,16.9)$ & $<0.01$ & 3.82 & $(1.51,12.9)$ & 0.01 \\
\hline & 12-19years (ref) & & & & & & \\
\hline & 20-39 years & 1.24 & $(0.56,3.15)$ & 0.61 & 2.26 & $(0.64,14.3)$ & 0.28 \\
\hline & $40-59$ years & 2.21 & $(0.97,5.69)$ & 0.07 & 4.88 & $(1.36,31.2)$ & 0.04 \\
\hline & $>=60$ years & 4.03 & $(1.59,11.28)$ & $<0.01$ & 9.47 & $(2.45,62.90)$ & $<0.01$ \\
\hline & Gender (ref female) & 1.08 & $(0.70,1.70)$ & 0.74 & 1.82 & $(1.00,3.51)$ & 0.05 \\
\hline \multirow[t]{6}{*}{ Admission } & Motorised PMD (ref non-motorised) & 2.16 & $(1.26,3.90)$ & $<0.01$ & 1.80 & $(1.04,3.29)$ & 0.04 \\
\hline & $12-19$ years (ref) & & & & & & \\
\hline & 20-39 years & 1.31 & $(0.65,2.87)$ & 0.48 & 1.38 & $(0.63,3.34)$ & 0.45 \\
\hline & 40-59 years & 1.85 & $(0.89,4.17)$ & 0.12 & 2.03 & $(0.90,5.07)$ & 0.10 \\
\hline & $>=60$ years & 4.75 & $(2.02,11.88)$ & $<0.01$ & 4.72 & $(1.86,13.03)$ & $<0.01$ \\
\hline & Gender (ref female) & 1.37 & $(0.91,2.09)$ & 0.14 & 1.23 & $(0.79,1.94)$ & 0.36 \\
\hline
\end{tabular}


Table 3 Factors associated with severe injury or admission: scooters vs e-scooters subgroup $(n=440)$

\begin{tabular}{|c|c|c|c|c|c|c|c|}
\hline \multirow{2}{*}{$\begin{array}{l}\text { Outcome } \\
\text { Severe Injury }\end{array}$} & \multirow{2}{*}{$\begin{array}{l}\text { Variables } \\
\text { Motorised PMD (ref non-motorised) }\end{array}$} & \multicolumn{3}{|c|}{$\begin{array}{l}\text { Univariate } \\
\text { Odds Ratio, }(95 \%(1), p \text { value }\end{array}$} & \multicolumn{3}{|c|}{$\begin{array}{l}\text { Multivariable } \\
\text { Odds Ratio, }(95 \% \text { Cl), p value }\end{array}$} \\
\hline & & 3.97 & $(1.18,24.8)$ & $<0.01$ & 3.78 & $(1.11,23.65)$ & $<0.01$ \\
\hline & $12-19$ years (ref) & & & & & & \\
\hline & 20-39 years & 2.43 & $(0.48,44.50)$ & 0.39 & 2.51 & $(0.49,46.17)$ & 0.38 \\
\hline & $40-59$ years & 4.51 & $(0.87,83.00)$ & 0.15 & 4.74 & $(0.9,87.72)$ & 0.14 \\
\hline & $>=60$ years & 6.67 & $(1.12,128.00)$ & $<0.01$ & 6.00 & $(0.99,115.78)$ & 0.10 \\
\hline & Gender (ref female) & 2.31 & $(1.12,5.41)$ & 0.03 & 2.24 & $(1.07,5.30)$ & 0.04 \\
\hline \multirow[t]{6}{*}{ Admission } & Motorised PMD (ref non-motorised) & 1.28 & $(0.66,2.65)$ & 0.48 & 1.25 & $(0.64,2.59)$ & 0.54 \\
\hline & $12-19$ years (ref) & & & & & & \\
\hline & 20-39 years & 0.89 & $(0.35,2.59)$ & 0.83 & 0.91 & $(0.35,2.66)$ & 0.86 \\
\hline & $40-59$ years & 1.22 & $(0.46,3.63)$ & 0.70 & 1.25 & $(0.47,3.73)$ & 0.67 \\
\hline & $>=60$ years & 2.24 & $(0.73,7.49)$ & 0.17 & 2.18 & $(0.71,7.34)$ & 0.19 \\
\hline & Gender (ref female) & 1.34 & $(0.83,2.23)$ & 0.24 & 1.27 & $(0.78,2.13)$ & 0.34 \\
\hline
\end{tabular}

with the risk-taking profile found in other studies [3, 13-17, 28].

MotPMD-related reasons such as higher travelling speeds [4, 17, 19], and environmental issues such as lack of dedicated lanes vs usage of mixed-use conventional bicycle lanes, sidewalks or roads have also been proposed as contributory factors to injury [18]. MotPMD-related legislation varies between countries. In the European Union, MotPMDs are barred from motor vehicle roads, and are allowed only on sidewalks at speeds $<6 \mathrm{~km} / \mathrm{hr}$. [35]. In the United States, there is great variability between the states, with some permitting road usage [35]. In Singapore, new legislation (Active Mobility Act) now restricts use to only sidewalks or shared bicycle lanes, but at maximum speed of $25 \mathrm{~km} / \mathrm{hr}$. Our study was conducted prior to the implementation of the new regulations. Future studies focusing on interventional strategies for injury prevention would be of great policy interest, such as examining the differences in incidence and economic burden of PMD-related injury before and after legislative rules controlling MotPMD use, especially given the significant association of MotPMDs with severe injury and admissions.

The main strength of our study was that it covered all the public-sector institutions nation-wide in an urban multi-ethnic population. However, the use of NTR data had some limitations. Certain information such as PMD type and helmet use was incomplete. Nevertheless, data quality was good for injury severity and need for hospital admission, data that is routinely collected by the NTR. Another limitation is that the NTR only captures data for patients who present to the emergency department of public hospitals, and hence our study findings may not apply to riders who self-medicate or see their family physician.

\section{Conclusion}

MotPMD riders had triple the risk of severe injury and double the risk of requiring hospitalisation compared to NonPMDs. Increased age was also associated with severe injury and requiring hospitalisation.

\section{Abbreviations}

ISS: Injury Severity Score; MotPMD: Motorised Personal Mobility Device; NonPMD: Non-motorised Personal Mobility Device; NTR: National Trauma Registry; PMD: Personal Mobility Device

\section{Acknowledgements}

The authors would like to thank the National Trauma Committee, the National Trauma Registry working group, the National Trauma Unit, and other trauma database coordinators of the National Trauma Registry.

The following trauma co-ordinators and trauma service representatives from the Changi General Hospital, Khoo Teck Puat Hospital, National University Hospital, Ng Teng Fong General Hospital, Sengkang General Hospital, Singapore General Hospital and Tan Tock Seng Hospital, Singapore contributed to this paper:

Chee Keong, Chong. Changi General Hospital, Singapore. Haslizah Bte Hassan. Changi General Hospital, Singapore. Serena, Koh. Changi General Hospital, Singapore. Yan, Li. Changi General Hospital, Singapore. Kebing, Lin. Changi General Hospital, Singapore. Nadhirah Binte Sani. Changi General Hospital, Singapore. Peifu, Ng. Changi General Hospital, Singapore.

Christelle, Cha Sow King. Khoo Teck Puat Hospital, Singapore.

Tiong Thye, Goo. Khoo Teck Puat Hospital, Singapore.

Woan Wui, Lim. Khoo Teck Puat Hospital, Singapore.

Michael, Liu. Khoo Teck Puat Hospital, Singapore.

Sanjay, Patel. Khoo Teck Puat Hospital, Singapore.

Hong Chuen, Toh. Khoo Teck Puat Hospital, Singapore.

Suat Ting, Lim. National University Hospital, Singapore.

Tian Zhi, Lim. National University Hospital, Singapore.

Lynette Mee Ann, Loo. National University Hospital, Singapore.

Sabrina Siok Buay, Yeo. National University Hospital, Singapore.

Antony, Gardner. Ng Teng Fong General Hospital, Singapore.

Kai Yin, Hwang. Ng Teng Fong General Hospital, Singapore.

Noor'Aini Binte Nordin. Ng Teng Fong General Hospital, Singapore.

Yee Kent, Liew. Sengkang General Hospital, Singapore.

Jen Heng, Pek. Sengkang General Hospital, Singapore.

Pei Leng, Chong. Singapore General Hospital, Singapore.

Norhayati Mohamed Jainodin, Singapore General Hospital, Singapore.

Seo Kiat, Goh. Singapore General Hospital, Singapore.

Chung Fai Jeremy, Ng. Singapore General Hospital, Singapore. 
Teng Teng, Fiona, Peh. Singapore General Hospital, Singapore.

Mann Hong, Tan. Singapore General Hospital, Singapore.

Choon Peng Jeremy, Wee. Singapore General Hospital, Singapore.

Yew Lok, Woo. Singapore General Hospital, Singapore.

Jolene YX, Cheng. Tan Tock Seng Hospital, Singapore.

Karen Tsung Shyen, Go. Tan Tock Seng Hospital, Singapore.

Serene SN, Goh. Tan Tock Seng Hospital, Singapore.

Xin Yi, Leong. Tan Tock Seng Hospital, Singapore.

Li-Tserng, Teo. Tan Tock Seng Hospital, Singapore.

\section{Authors' contributions}

THW conceived and designed the study. ALT, THW and NN performed the data analysis. ALT drafted the initial manuscript with all authors contributing substantially to the final manuscript. All authors read and approved the final manuscript. THW takes responsibility for the paper as a whole.

\section{Funding}

The authors received no specific individual funding for this work.

\section{Availability of data and materials}

The de-identified data from this study was obtained from the respective trauma offices of the participating hospitals, after permissions were sought and granted from the respective trauma office directors upon proof of ethical approval.

This data is also submitted to the National Trauma Registry, established and funded by Singapore's Ministry of Health. Pooled and de-identified data may be available from the National Registry of Diseases Office in Singapore for researchers who meet the criteria for access to confidential data. Details are available at https://www.nrdo.gov.sg/faq.

\section{Ethics approval and consent to participate}

The corresponding author's Institutional Review Board (Singapore General Hospital, Singapore Health Services) granted ethical approval for this retrospective study, reference number 2014/155/D, with waiver of informed consent granted as only secondary retrospective and de-identified data was used.

\section{Consent for publication}

Not applicable

\section{Competing interests}

The authors declare that they have no competing interests.

\section{Author details}

${ }^{1}$ Preventive Medicine, National University Hospital, 1 E Kent Ridge Road, NUHS Tower Block, Level 12, Singapore 119228, Singapore. ${ }^{2}$ Health Services Research Unit, Singapore General Hospital, 226 Outram Road, 169039 Singapore, Singapore. ${ }^{3}$ Centre for Quantitative Medicine, Duke-National University of Singapore Graduate Medical School, 8 College Rd, Singapore 169857, Singapore. ${ }^{4}$ Singapore General Hospital/Duke-National University of Singapore Graduate Medical School, Outram Road, Singapore 169608, Singapore. ${ }^{5}$ Department of General Surgery, Singapore General Hospital, Outram Road, Singapore 169608, Republic of Singapore.

Received: 27 November 2018 Accepted: 20 June 2019 Published online: 04 July 2019

\section{References}

1. Papoutsi S, Martinolli L, Braun CT, Exadaktylos AK. E-bike injuries: experience from an urban emergency department-a retrospective study from Switzerland. Emergency medicine international. 2014;2014:850236.

2. Du W, Yang J, Powis B, Zheng X, Ozanne-Smith J, Bilston L, He J, Ma T, Wang X, Wu M. Epidemiological profile of hospitalised injuries among electric bicycle riders admitted to a rural hospital in Suzhou: a crosssectional study. Inj Prev. 2014;20(2):128-33.

3. Weber T, Scaramuzza G, Schmitt KU. Evaluation of e-bike accidents in Switzerland. Accid Anal Prev. 2014;73:47-52.

4. Zhang X, Yang Y, Yang J, Hu J, Li Y, Wu M, Stallones L, Xiang H. Road traffic injuries among riders of electric bike/electric moped in southern China. Traffic injury prevention. 2018;19(4):417-22.
5. Zhou SA, Ho AFW, Ong MEH, Liu N, Pek PP, Wang YQ, Jin T, Yan GZ, Han $\mathrm{NN}$, Li G. Electric bicycle-related injuries presenting to a provincial hospital in China: a retrospective study. Medicine. 2017;96(26):e7395.

6. Tenenbaum S, Weltsch D, Bariteau JT, Givon A, Peleg K, Thein R, Group IT. Orthopaedic injuries among electric bicycle users. Injury. 2017;48(10):2140-4.

7. Al-Kashmiri A, Hasan AQ, Al-Shaqsi S. Rolling danger: the epidemiology of injuries caused by hover boards in the United States in five years (2011-2016). J Emerg Crit Care Med. 2017;1(11).

8. Mcllvain C, Hadiza G, Tzavaras TJ, Weingart GS. Injuries associated with hoverboard use: a review of the National Electronic Injury Surveillance System. Am J Emerg Med. 2019;37(3):472-7.

9. Schapiro AH, Lall NU, Anton CG, Trout AT. Hoverboards: spectrum of injury and association with an uncommon fracture. Pediatr Radiol. 2017:47(4):437-41.

10. Siracuse BL, Ippolito JA, Gibson PD, Beebe KS. Hoverboards: a new cause of pediatric morbidity. Injury. 2017:48(6):1110-4.

11. Sobel AD, Reid DB, Blood TD, Daniels AH, Cruz Al. Pediatric orthopedic hoverboard injuries: a prospectively enrolled cohort. J Pediatr. 2017;190:271-4.

12. Gross I, Weiss DJ, Eliasi E, Bala M, Hashavya S. E-bike-related trauma in children and adults. J Emerg Med. 2018;54(6):793-8.

13. Hu F, Lv D, Zhu J, Fang J. Related risk factors for injury severity of e-bike and bicycle crashes in Hefei. Traffic injury prevention. 2014;15(3):319-23.

14. Bai L, Liu P, Guo Y, Yu H. Comparative analysis of risky behaviors of electric bicycles at signalized intersections. Traffic injury prevention. 2015;16(4):424-8.

15. Yang J, Hu Y, Du W, Powis B, Ozanne-Smith J, Liao Y, Li N, Wu M. Unsafe riding practice among electric bikers in Suzhou, China: an observational study. BMJ Open. 2014;4(1):e003902.

16. Wu C, Yao L, Zhang K. The red-light running behavior of electric bike riders and cyclists at urban intersections in China: an observational study. Accid Anal Prev. 2012;49:186-92.

17. Haustein S, Møller M. E-bike safety: individual-level factors and incident characteristics. J Transp Health. 2016;3(3):386-94.

18. Siman-Tov M, Radomislensky I, Group IT, Peleg K. The casualties from electric bike and motorized scooter road accidents. Traffic injury prevention. 2017;18(3):318-23.

19. Cherry $C R$, Yang $H$, Jones $L R$, He M. Dynamics of electric bike ownership and use in Kunming, China. Transport Policy. 2016:45:127-35.

20. Singapore Health Facts [https://www.moh.gov.sg/resources-statistics]. Accessed 24 Nov 2018.

21. Baker SP, O'neill B. The injury severity score: an update. J Trauma Acute Care Surg. 1976;16(11):882-5.

22. O'Reilly GM, Gabbe B, Cameron PA. Trauma registry methodology: a survey of trauma registry custodians to determine current approaches. Injury. 2015; 46(2):201-6.

23. Wong TH, Nguyen HV, Chiu MT, Chow KY, Ong ME, Lim GH, Nadkarni NV, Bautista DC, Cheng JY, Loo LM, Seow DC. The low fall as a surrogate marker of frailty predicts long-term mortality in older trauma patients. PLoS One. 2015;10(9):e0137127. https://doi.org/10.1371/journal.pone.0137127.

24. Wong TH, Krishnaswamy G, Nadkarni NV, Nguyen HV, Lim GH, Bautista DCT, Chiu MT, Chow KY, Ong MEH. Combining the new injury severity score with an anatomical polytrauma injury variable predicts mortality better than the new injury severity score and the injury severity score: a retrospective cohort study. Scandinavian Journal of Trauma, Resuscitation and Emergency Medicine. 2016;24(1):25.

25. Wong TH, Nadkarni NV, Nguyen HV, Lim GH, Matchar DB, Seow DCC, King NKK, Ong MEH. One-year and three-year mortality prediction in adult major blunt trauma survivors: a National Retrospective Cohort Analysis. Scand J Trauma Resusc Emerg Med. 2018;26(1):28.

26. Sammy I, Lecky F, Sutton A, Leaviss J, O'Cathain A. Factors affecting mortality in older trauma patients-a systematic review and meta-analysis. Injury. 2016;47(6):1170-83.

27. Beck B, Cameron P, Lowthian J, Fitzgerald M, Judson R, Gabbe BJ. Major trauma in older persons. BJS open. 2018;2(5):310-8.

28. Hsieh CH, Liu HT, Hsu SY, Hsieh HY, Chen YC. Motorcycle-related hospitalizations of the elderly. Biom J. 2017:40(2):121-8.

29. Hashmi A, Ibrahim-Zada I, Rhee P, Aziz H, Fain MJ, Friese RS, Joseph B. Predictors of mortality in geriatric trauma patients: a systematic review and meta-analysis. The journal of trauma and acute care surgery. 2014;76(3):894-901.

30. Frankenfield D, Cooney RN, Smith JS, Rowe WA. Age-related differences in the metabolic response to injury. J Trauma. 2000;48(1):49-56 discussion 56-47.

31. Banks SE, Lewis MC. Trauma in the elderly: considerations for anesthetic management. Anesthesiol Clin. 2013;31(1):127-39. 
32. Bonne S, Schuerer DJ. Trauma in the older adult: epidemiology and evolving geriatric trauma principles. Clin Geriatr Med. 2013;29(1):137-50.

33. Llompart-Pou JA, Perez-Barcena J, Chico-Fernandez M, Sanchez-Casado M, Raurich JM. Severe trauma in the geriatric population. World journal of critical care medicine. 2017;6(2):99-106.

34. Reske-Nielsen C, Medzon R. Geriatric Trauma. Emerg Med Clin North Am. 2016;34(3):483-500.

35. Litman T, Blair R: Managing Personal Mobility Devices (PMDs) On Nonmotorized Facilities; 2019

\section{Publisher's Note}

Springer Nature remains neutral with regard to jurisdictional claims in published maps and institutional affiliations.

Ready to submit your research? Choose BMC and benefit from:

- fast, convenient online submission

- thorough peer review by experienced researchers in your field

- rapid publication on acceptance

- support for research data, including large and complex data types

- gold Open Access which fosters wider collaboration and increased citations

- maximum visibility for your research: over $100 \mathrm{M}$ website views per year

At $B M C$, research is always in progress.

Learn more biomedcentral.com/submissions 